\title{
Partial maxillary osteotomy following an unsuccessful forced eruption of an impacted maxillary canine - 10 year follow-up. Review and case report
}

\author{
Edela PURICELLI' ${ }^{1}$, Mário Alexandre MORGANTI ${ }^{2}$, Henrique Voltollini de AZAMBUJA ${ }^{3}$, Deise PONZONI ${ }^{4}$, Clarice C. \\ FRIEDRISCH ${ }^{5}$
}

\begin{abstract}
1- BDS, MSc, PhD Professor and Head of the Department of Oral and Maxillofacial Surgery, Clinics Hospital of Porto Alegre, School of Dentistry, Federal University of Rio Grande do Sul - UFRGS, Porto Alegre, RS, Brazil.

2- BDS, DDS, MSc, School of Dentistry, Pontifical University of Rio Grande do Sul - PUCRS; Orthodontist, PhD student, Department of Dentistry, Irmandade Santa Casa de Misericórdia de Porto Alegre, Porto Alegre, RS, Brazil.

3- BDS, MSc, Phd Student, School of Dentistry, Federal University of Rio Grande do Sul - UFRGS; Oral and Maxillofacial Surgeon, Department of Dentistry, Irmandade Santa Casa de Misericórdia de Porto Alegre, Porto Alegre, RS, Brazil.

4- BDS, MSc, PhD Professor, Department of Oral and Maxillofacial Surgery, Clinics Hospital of Porto Alegre, School of Dentistry, Federal University of Rio Grande do Sul - UFRGS, Porto Alegre, RS, Brazil.

5- BDS, Orthodontist, School of Dentistry, Federal University of Rio Grande do Sul - UFRGS, Porto Alegre, RS, Brazil.
\end{abstract}

Corresponding address: Edela Puricelli - ortodontia.morganti@me.com - Phone/Fax:(51)3334-5060 - Quintino Bocaiuva, 465 - Porto Alegre, RS - 90440 051 - e-mail: epuricelli@uol.com.br

Received: March 22, 2012 - Modification: September 05, 2012 - Accepted: October 0, 2012

\section{ABSTRACT}

\begin{abstract}
The maxillary canines are amongst the most frequently impacted teeth, second only to the third molars. Several conservative orthodontic and surgical techniques are available to position the teeth properly in the dental arch, even in severe cases. However, when an extraction is necessary, it often leaves a critical alveolar defect of difficult management. The authors present the technique of Partial Maxillary Osteotomy, in which a dento-alveolar segment is moved mesially, hence closing the remaining space, allowing for the formation of healthy periodontium and resulting in an adequate functional and aesthetic outcome. A case report is presented with a 10 year follow-up, proving the technique's stability in the long term.
\end{abstract}

Key words: Impacted tooth. Osteotomy. Tooth extraction. Mouth rehabilitation.

\section{INTRODUCTION}

A tooth is considered impacted when it does not erupt within its expected physiological time ${ }^{17}$ or if it has not completed erupting until six months after the homologous has been positioned in the dental arch, with a complete radicular formation ${ }^{14}$. Canine impaction is a relatively common condition, affecting about $1-2 \%$ of the population and representing about $18 \%$ of all impacted teeth ${ }^{20}$. The maxillary arch is affected in about $80-90 \%$ of all cases of canine impaction ${ }^{12}$.

The maxillary canine plays a key role in the functional aspects of the bite, taking part of the anterior guidance either on a canine protected occlusion or group function. In order to support great vertical and lateral loads, it has a large root surface area, which, in contrast, becomes a great orthodontic challenge when complex movements are needed $5,6,19$. The volume of its root and the shape of its crown are important predicates for the perception of a young and healthy smile $e^{5,6,19}$.

The maxillary canines are more frequently impacted on the palatal aspect in a proportion of $3: 1$. This may place them on a horizontal position that will make treatment increasingly more complex ${ }^{5,6}$.

Orthodontic approaches to position the upper canine mostly resort to maxillary expansion and space opening, which, amongst others, must relate to the age, development and dental-skeletal characteristics of the patient. Those approaches 
attempt to avoid impaction or the future need for extraction.

Impaction may be systemic or local in etiology ${ }^{6,18}$. Amongst the local causes, root dilaceration and anquilosys must be emphasized ${ }^{6,18}$. Those, when located on the apical third of the impacted maxillary canine's root, close or into the apex of a triangular pyramid formed by the conjunction of the nasal, sinusal and alveolar corticals, also called the Ennis inverted $\mathrm{Y}$, oblige the clinician to produce precise diagnostics ${ }^{17,18}$.

In these situations, intra and extra-oral radiographic examinations are necessary for a suitable evaluation of the affected region, including tridimensional images, generated by cone-beam computed tomography $2,9,16,18$.

When orthodontic treatment alone will be limited, canine impaction gains an indication of surgical intervention, which may be conservative or radical. As conservative techniques we may quote exposure for expontaneous eruption, surgical orthodontic traction ${ }^{6,9,17}$, volumetric reconstruction of the alveolar bone ${ }^{10}$, and apicotomy ${ }^{17,18}$.

Radical treatment is recommended when conservative orthodontic or surgical techniques are unsuccessful or contra-indicated. Usually when there is little to non-existing space for the canine and nearly acceptable occlusion, orthodontic traction attempts that require great distal movements of the posterior teeth or extraction of the first pre-molar should be avoided ${ }^{1,4,9,15,19}$. When orthodontic traction is attempted and does not succeed, even with no clear observable obstruction, it is usually due to apical root dilacerations, improper orthodontic force direction, surgical wire retentions or ankylosis ${ }^{4,6,15,17}$.

When, after six months of orthodontic force application, the tooth does not show clear evidence of movement, a re-evaluation is necessary. Orthodontic planning must be accessed. If the tooth is submerged, surgical re-intervention is recommended ${ }^{1,4,15}$. If the canine's apical third is situated by the Enny's inverted $Y$ or if signs of apical root dilacerations are visible, an apicotomy, if not yet performed, must be undertaken ${ }^{18}$. If, after all these measures were accounted for with no prognosis of success, radical treatment by means of extraction is recommended ${ }^{9,19}$.

The resulting interdental space is usually characterized by the significant loss of alveolar bone and soft tissue. Partial Maxillary Osteotomy, as it is proposed here, arises as a plausible technique to correct the local bone structures. Mobilization of the distal dento-alveolar segment allows for an anterior displacement of the posterior teeth and supporting structures, closing the extraction space and re-establishing the occlusion ${ }^{17}$.

In pre-operatory, the patient's oral and systemic conditions must be evaluated. The presence of a proper orthodontic device must be appraised. If present, it must be accessed for appliance selection and setup. If not, a passive appliance, with rectangular steel arch wires, must be prepared to allow for intermaxillary fixation ${ }^{6,17}$.

The occlusion should be checked on stone models, predicting the desired surgical movements. If severe interference is noted, a pre-surgical orthodontic stage might be necessary.

\section{CASE REPORT}

A 17 year old female patient was referred in 2001 , after 31 months of orthodontic treatment. On $12 / 29 / 1998$, during this previous treatment time she underwent surgery, when a device was placed for orthodontic traction of the maxillary right canine, resulting in an unfavorable outcome. No notable particularities could be found, both upon current anamneses and a physical exam. In the course of the intra-oral exam, an orthodontic device could be seen with an open coil spring between teeth 12 and 14 for space maintenance (Figure $1 \mathrm{~A}$ ). Tooth 13, with transalveolar inclination, presented

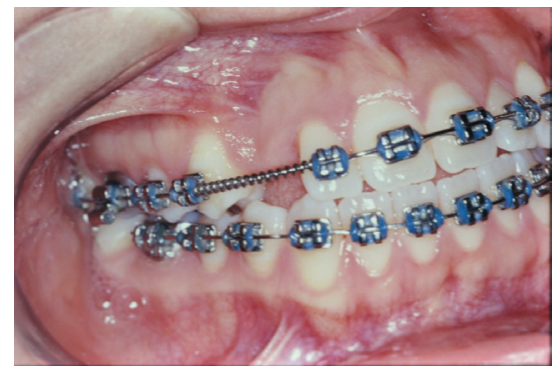

A

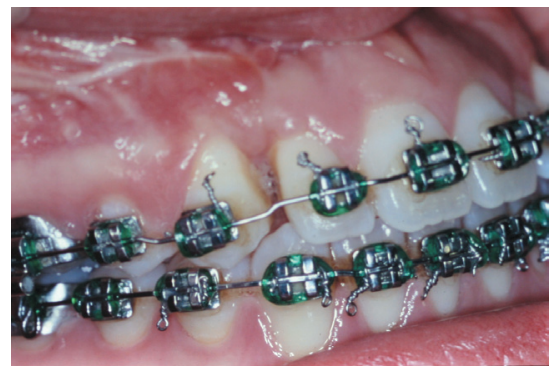

B

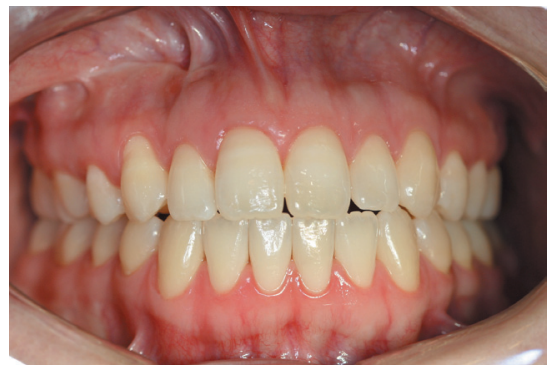

C

Figure 1-A. Preoperatory aspect. Orthodontic appliance was used to open space for the right maxillary canine traction. B. Oclusion in 30 days postoperative control. Tooth 14 substitutes the lost canine, with closure of the space, in the horizontal immobilization stage, prior to orthodontic alignment. C. Clinical control of 10 years and 10 months postoperatively. Orthodontic appliances were removed for 10 years and 3 months. Patient's occlusion maintains excellent functional and esthetic result 
clinical exposure of its crown on the palate, with its vestibular face mesially rotated and three orthodontic buttons still present for elastic traction (Figure 2A).

Periapical and panoramic radiographic exams, dating from January 14, 2001, reveal tooth's 13 apex constrained within the Ennis inverted $\mathrm{Y}$. Significant bone loss could also be seen distal to 12 and mesial to 14 (Figures 3A, 4A).

Previous history substantially reduced expectations for success in future attempts of surgical orthodontic traction. Although the patient was well within a favorable age (13-19 years $\left.{ }^{9}\right)$, proper orthodontic treatment was conducted with space opening and well directed inter-arch elastic force for much beyond the necessary time, without distinguishing signs of tooth movement. After the patient and her parents were advised about the possible prosthetic rehabilitation alternatives, they were favorable to the indication of partial maxillary osteotomy.

The appliance selection must conform to the orthodontist prescription. In addition, it is recommended that the brackets, with hooks or kobayashi on the posterior teeth, be properly bonded and accessed for resistance. A rigid passive rectangular wire is necessary, preferably $.019^{\prime \prime} x .025^{\prime \prime}$. The arch-wire should be continuous in the mandibular arch and segmented in the maxillary arch, separating the mesial and distal segments. The wire ends must be properly bent to protect the surgeon. A .025 $\mathrm{mm}$ steel ligature wire may be used as a tie-together to stabilize the mesial and distal segments as rigid units, not allowing individual tooth movements. Anterior hooks or kobayashi should be placed in the upper and lower arches. Lastly, orthodontic buttons should be bonded on the palatal side of the bicuspids on the distal segment, to allow for cross-bite elastics.

The surgery took place on March 02, 2001, under general anesthesia. The procedure was comprised of the maxillary right canine removal and a partial maxillary osteotomy, with mobilization of the alveolar distal segment containing teeth 14 to 17. After the orthodontic wire was sectioned, bicortical osteotomies, vestibular and palatal, were performed, on both the horizontal and vertical aspects. Fractures were performed with straight and curved chisels, allowing for the liberation of the distal dento-alveolar segment. Vertical osteotomies enabled the establishment of a breach in the alveolar process where the liberated segment was moved into, in a mesial direction, nearly closing the gap. Aiming to preserve any residual viable periodontium, attention was given to maintain an approximate $1.5 \mathrm{~mm}$ margin of bone distal to 12 and mesial to 14. Post-surgically, by means of elastic traction, the approximation of the distal segment was concluded. A single straight spaced $1.5 \mathrm{~mm}$ titanium miniplate with 4 holes, fixed with 4 titanium miniscrews $4 \mathrm{~mm}$ long, was used for the osteosynthesis. Areas of ischemic formation of the gingiva could be observed during the suture, which were eliminated by resizing the traction elastics, thus reinforcing the significance of proper orthodontic anchorage.

Intermaxillary immobilization was sustained for 21 days and during weekly postoperatory controls.

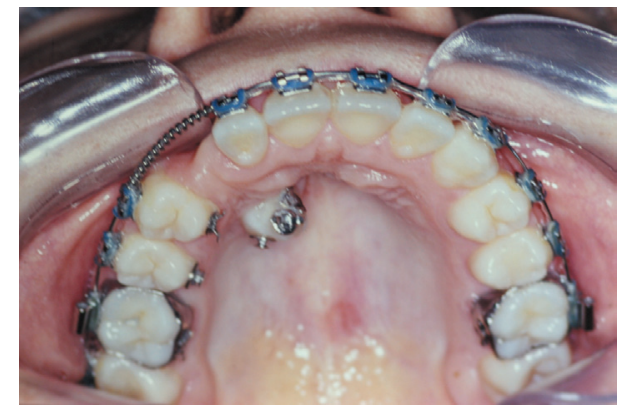

A

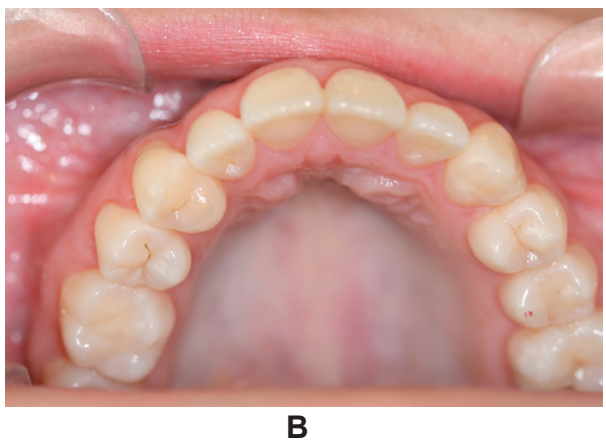

B

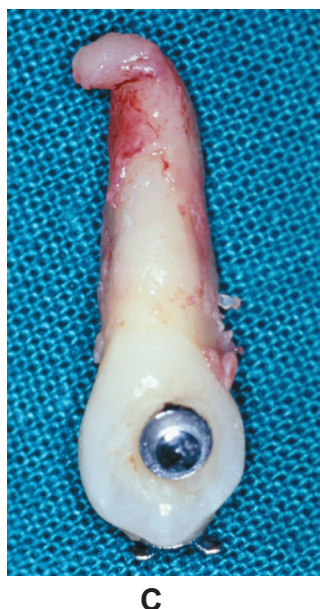

Figure 2- Palatal view. A. Preoperatory. Tooth 13 partially erupted in a transalveolar position with the crown mesially inclined. Note the presence of three orthodontic traction devices. B. Clinical control of 10 years and 10 months postoperatively, with orthodontic appliance removed for 10 years and 3 months, thus confirming stability. Vestibular and palatal gingival contour is maintained. C. Extracted maxillary right canine. Severe apical dilaceration is observed, along with areas compatible with periodontal alterations, possibly related to root ankylosis 


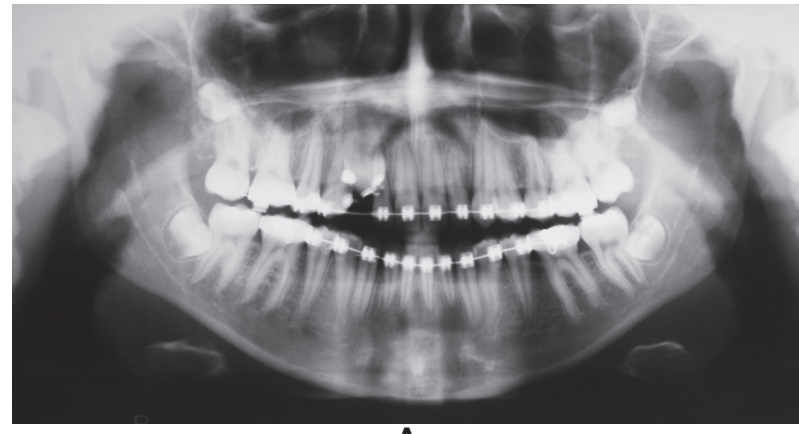

A

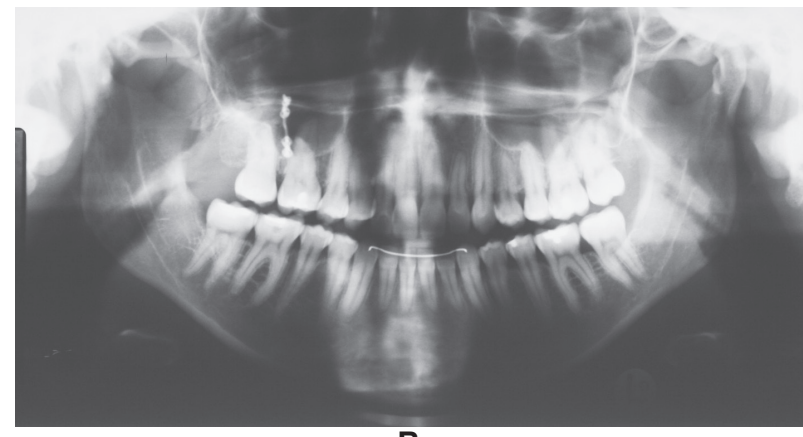

B

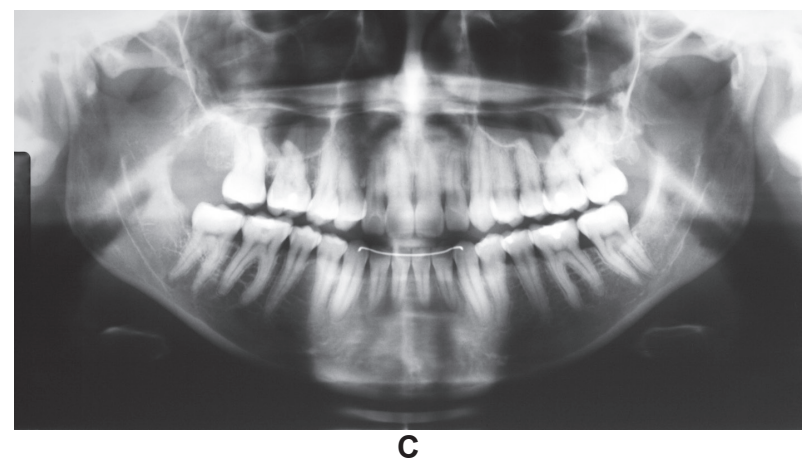

Figure 3- Panoramic radiographic sequence. A. Preoperative aspect dating from January 14, 2001. Alveolar bone loss is noticeable along the misaligned impacted canine's crown. B. Control of October, 2010. The osteosynthesis titanium miniplate is still present. Alveolar bone neoformation and remodeling are completed with the mobilization and approximation of the posterior segment. C. Following removal of the fixation, panoramic radiographic control of January, 17, 2012

When the elastics were removed and exchanged for new ones, mandibular movement was encouraged. After three weeks, the segmented orthodontic arch-wire was substituted for a continuous arch, maintaining stability of the segment and sustaining the formation of a callus.

The patient was cleared for orthodontic movements in April 24, 2001. Full treatment was concluded on October 23, 2001, 7 months and 21 days later, with braces removal and installation of removable retainers. After 9.7 years, on October 29, 2010, due to patient request, the internal rigid fixation was removed. On the clinical and radiographic control of January 10 and 17, 2012
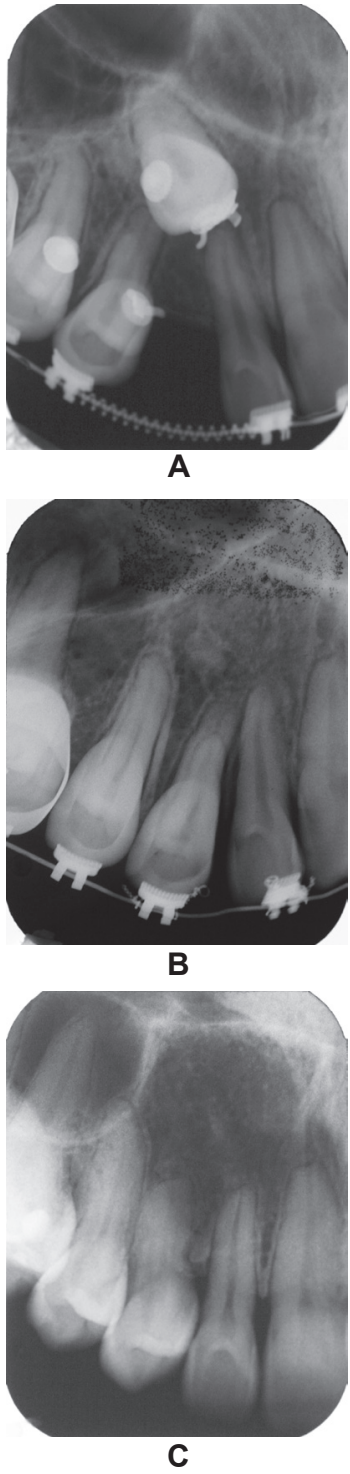

Figure 4- Periapical radiographic sequence. A. Preoperatory image of January 14,2001 . The root apex is perfectly identifiable situated between the nasal and sinusal cortical, area named the Ennis inverted $Y$. In this image, root dilaceration is not noticeable. B. Periapical radiography of September 10,2001, corresponding to 4 months and 7 days following surgery. Alveolar bone height may be observed between teeth 12 and 14 with the distal dental-alveolar segment approximation. C. Periapical radiography of January 17,2001 , corresponding to 10 years and 10 months following surgery. Space closure and complete bone neoformation and remodeling are apparent, typifying normal physiology of the area. All involved teeth maintain pulpar vitality

(Figures 1C, 2B, 3C, 4C), both stability and pulpar vitality could be confirmed after 10 years and 10 months of follow-up with excellent periodontal conditions. 


\section{DISCUSSION}

During the orthodontic traction of an impacted tooth after surgical placement of a device, an improvement must be perceived, on average, in about 6 to 8 months. With a lack of a distinguishable response, the passing of this period must be an alert to possible complications. Subsequent attempts with ever increasing traction forces may provoke periradicular trauma, aggravating the underlying conditions and leading to ankylosis. Optimal orthodontic force to erupt the impacted teeth might be as subtle as 50 grams, and preferably not over 150 grams $^{5-7,9,11,15}$.

The analysis of the image exams must be extended beyond the simple verification of impaction. Especially regarding the maxillary canines, not only should the position of its crown should be accessed, but also its long axis inclination and relation to the adjacent teeth ${ }^{3,5,6}$, the root's apical region must receive appropriate attention and interpretation, so that, if needed, a surgical technique may be correctly prescribed. According to Puricelli ${ }^{18}$ (2007), root apex dilaceration and ankylosis might be eliminated by means of apicotomy. In this case, a macroscopic examination of the extracted tooth confirmed severe apical root dilacerations (Figure 2C).

When, after a traction attempt, the maxillary canine remains impacted or has been extracted, a great deal of alveolar bone volume is lost. Besides the space gained or maintained in the dental arch, it's not uncommon that the formation of an alveolar defect greatly reduces the possibilities for an acceptable outcome on the prosthetic rehabilitation in terms of function and aesthetics. The absence of a cuspid's root eminence might contribute to alterations in the gingival shape and tonality ${ }^{8,13}$ (Figure 1A).

Since it involves multiple teeth, partial maxillary osteotomy might be used to mobilize an entire segment, closing the space created by the loss of a tooth ${ }^{17}$. Besides this outcome, with all the teeth contained within their alveolus and now approximated, a significant gain in bone volume is perceived, maintaining the integrity of the periodontium and all the supporting structures in the adjacent teeth (Figures 1B-C, 4B-C).

The dental-alveolar segment must be partially fixated during the surgical procedure with metalic wire for osteosynthesis or titanium miniplates and miniscrews (Figure $3 \mathrm{~B}$ ). It is important that some degree of mobility should exist, 45 to 60 days post-operatory, during osseous neoformation and remodeling, independently of the system used. Tissue plasticity during this period is what allows for the complete closure of the gap, also providing gingival health (Figure 1B-C, 2B). It must be added that all teeth involved in this treatment, including all the posterior teeth in the mobilized segment, maintain pulpar vitality. Such an outcome is viable because the osteotomies are performed distant to the root apices. Afterwards, orthodontic movement follows its course (Figure 1C, 3C, 4C).

The maxillary partial osteotomy, as an operatory technique, allows for the extraction of the impacted canine, either previously or in the same surgical intervention. In the case of a complex impaction, or if preceded by frustrated attempts, with significant sequelae to the neighboring tissues, especially when palatine access is necessary, we recommend the tooth to be extracted first, in a distinguished moment. On average, after four months, once vascular nutrition is properly established, partial maxillary osteotomy might be performed.

As in the case of congenitally missing lateral incisors, so often treated by the mesial drift of the posterior teeth and orthodontically replaced for the permanent canines, by this approach, the lost canine's function is undertaken by the first bicuspid (Figures 1C, 2B, 3C). The literature reports on no long term adverse effects ${ }^{19}$. After 10 years and 10 months of control, we replicated the experiences of proper function and stability already described by the literature (Figures 1C, 2B, 3C).

\section{CONCLUSIONS}

Maxillary partial osteotomy, by mobilizing an alveolar bone segment, offers an efficient resolution for the correction of bone defects within the dental arches.

We shall indicate this technique within the concept of individual and multiple sustenance of integrity in occlusion and of the dental arches, especially in young patients, where the indication for fixed prosthetics or osseointegrated implants might be precocious.

Compared to the span of osseointegrated implant rehabilitation, with possible alveolar reconstruction, or orthodontic space closure, this technique offers a superior time efficient solution for the loss of the maxillary canines.

\section{REFERENCES}

1- Alessandri Bonetti G, Incerti Parenti S, Daprile G, Montevecchi $M$. Failure after closed traction of an unerupted maxillary permanent canine: diagnosis and treatment planning. Am J Orthod Dentofacial Orthop. 2011;140:121-5.

2- Alqerban A, Jacobs R, Fieuws S, Nackaerts O, SEDENTEXCT Project Consortium, Willems G. Comparison of 6 cone-beam computed tomography systems for image quality and detection of simulated canine impaction-induced external root resorption in maxillary lateral incisors. Am J Orthod Dentofacial Orthop. 2011;140:129-39.

3- Bass TB. Observations on the misplaced upper canine tooth. Dental Pract Dent Rec. 1967;18:25-33. 
4- Becker A, Chaushu G, Chaushu S. Analysis of failure in the treatment of impacted maxillary canines. Am J Orthod Dentofacial Orthop. 2010;137:743-54.

5- Bishara SE. Impacted maxillary canines: a review. Am J Orthod Dentofacial Orthop. 1992;101:159-71.

6- Bishara SE. Clinical management of impacted maxillary canines. Semin Orthod. 1998;4:87-98.

7- Bishara SE, Kommer DD, McNeil MH, Montagano LN, Oesterle LJ, Youngquist HW. Management of impacted canines. Am J Orthod. 1976;69:371-87.

8- Block MS. Treatment of the single tooth extraction site. Oral Maxillofac Surg Clin North Am. 2004;16:41-63.

9- Cappellette M, Cappellette Júnior M, Fernandes LCM, Oliveira AP, Oliveira WC. Palatine impacted permanent maxillary canines: diagnose and therapeutics. Rev Dent Press Ortodon Ortopedi Facial. 2008;13:60-73.

10- Conz MB, Granjeiro JM, Soares GA. Physicochemical characterization of six commercial hydroxyapatites for medicaldental applicatons as bone graft. J Appl Oral Sci. 2005;13:136-40. 11- Crescini A, Clauser C, Giorgetti R, Cortellini P, Pini Prato GP. Tunnel traction of infraosseous impacted maxillary canines. A three-year periodontal follow-up. Am J Orthod Dentofacial Orthop. 1994;105:61-72.

12- Dachi S, Howell FV. A survey of 3,874 routine full-month radiographs. II. A study of impacted teeth. Oral Surg Oral Med Oral Pathol. 1961;14:1165-9.
13- Indovina A Jr, Block MS. Comparison of 3 bone substitutes in canine extraction sites. J Oral Maxillofac Surg. 2002;60:53-8. 14- Lindauer SJ, Rubenstein LK, Hang WM, Andersen WC, Isaacson RJ. Canine impaction identified early with panoramic radiographs. J Am Dent Assoc. 1992;123:91-2,95-7.

15- Oliveira MV, Pithon MM. Attempted traction of impacted and ankylosed maxillary canines. Am J Orthod Dentofacial Orthop. 2012;142:106-14.

16- Oliveira-Santos C, Capelozza AL, Dezzoti MS, Fischer CM, Poleti ML, Rubira-Bullen IR. Visibility of the mandibular canal on CBCT cross-sectional images. J Appl Oral Sci. 2011;19:240-3.

17- Puricelli E. Retenção dentária: novos conceitos no tratamento ortocirúrgico. In: Gonçalves EAN, Feller C, editors. Atualização na clínica odontológica: a prática da clínica geral. São Paulo: Artes Médicas; 1998. p. 3-28.

18- Puricelli E. Apicotomy: a root apical fracture for surgical treatment of impacted upper canines. Head Face Med. 2007;3:33. 19- Silva OG Filho, Carvalho PM, Capelozza L Filho, Carvalho RM. Canine function performed by the premolar. Rev Dent Press Ortodon Ortopedi Facial. 2006;11:32-40.

20- Wolf JE, Mattila K. Localization of impacted maxillary canines by panoramic tomography. Dentomaxillofac Radiol. 1979;8:85-91. 